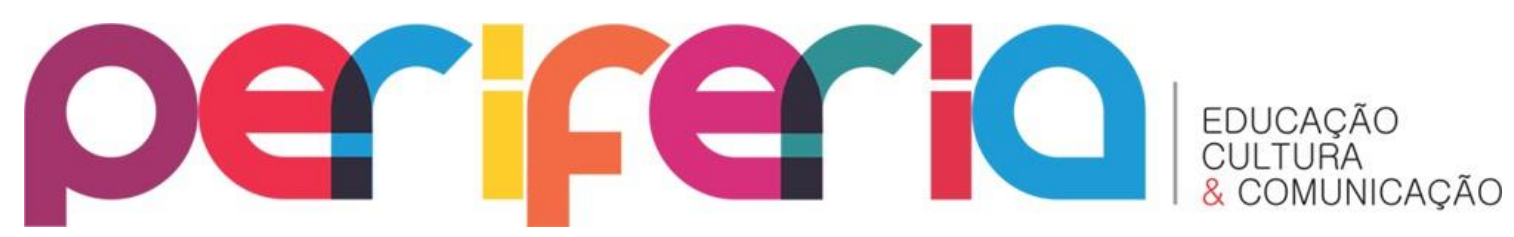

\title{
O FUNK NO RIO DE JANEIRO: IDENTIDADE ÉTNICA, CULTURAL E SOCIAL NA BAIXADA FLUMINENSE
}

\author{
Patricia Luisa Nogueira Rangel ${ }^{1}$ \\ Secretaria Municipal de Educação de Nova Iguaçu \\ Secretaria de Educação do Estado do Rio de Janeiro
}

\section{RESUMO}

O presente artigo objetiva explorar o movimento funk dentro da região periférica do Estado do Rio de Janeiro, a Baixada Fluminense. No entanto, este trabalho focará sua atenção nos municípios de Nova Iguaçu, Mesquita, Nilópolis, Belford Roxo, São João de Meriti e Duque de Caxias. O ritmo que contagiou jovens negros e pobres dos subúrbios e favelas do Rio de Janeiro não demorou muito para atingir o gosto musical de uma região sofrida e esquecida, tornando-se, para alguns, um modelo barato de diversão. 0 funk é um ritmo dançante que possibilitou recriações com a mistura de vários outros ritmos que estão diretamente relacionados à diáspora africana; junto com essa expressão cultural vem também a possibilidade de uma nova identidade, como linguajar, vestimenta, acessórios.

Palavras-chave: Funk, Baixada Fluminense, identidade, cultura.

THE FUNK IN RIO DE JANEIRO: ETHNIC, CULTURAL AND SOCIAL IDENTITY IN THE BAIXADA FLUMINENSE

\section{ABSTRACT}

This article aims to explore the funk movement in the peripheral region of the State of Rio de Janeiro, the Baixada Fluminense. However, this work will focus its attention to the municipalities of Nova Iguaçu, Mesquita, Nilópolis, Belford Roxo, São João de Meriti and Duque de Caxias. The contagious rhythm that blacks and poor youth of the suburbs and slums of Rio de Janeiro did not take long to reach the musical taste of a region suffering and forgotten, becoming, for some, a cheap model of fun. Funk is a dancing rhythm, which allowed recreations with mixing various other rhythms that are directly related to the African diaspora and cultural expression along with that also comes the possibility of a new identity, like language, clothing, accessories.

Key words: Funk, Baixada Fluminense, identity, culture.

\footnotetext{
${ }^{1}$ Mestre em Letras e Ciências Humanas pela UNIGRANRIO. Pós-graduada (lato sensu) em Língua Latina pela UERJ e Gestão e Coordenação Pedagógica pela AVM. Bacharel e Licenciada em Português/ Grego e respectivas literaturas pela Universidade do Estado do Rio de Janeiro. Professora da Secretaria Municipal de Educação de Nova Iguaçu e da Secretaria de Educação do Estado do Rio de Janeiro. E-mail: rangelluisa@ig.com.br
} 


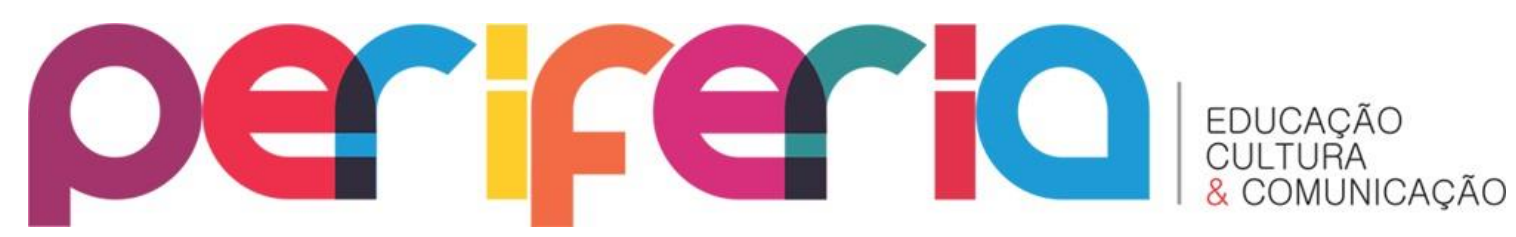

\section{INTRODUÇÃO}

Como professora do segundo segmento do ensino fundamental há 18 anos na rede municipal de Educação de Nova Iguaçu, tendo atuado nos bairros BNH e Edson Passos, antes da emancipação do município de Mesquita, em 1999, e nos bairros de Rosa dos Ventos, Tinguá e Califórnia, pude verificar que em todas essas regiões o funk é um ritmo que faz parte da vida dos jovens e contribui para a formação identitária desse grupo, ou seja, colabora para a formação de linguajar, vestimenta, adornos e posturas.

Com a implementação das Leis no $10.639 / 03$ e 11.645/08 ${ }^{2}$, que determinam a obrigatoriedade do ensino do estudo da História e Cultura Afro-brasileira e Indígena, e ciente da relação do funk com herança cultural afro, tendo em vista que o seu ritmo surgiu de grupos étnicos de pertença negra do movimento Black nos EUA e que sofreu adaptações culturais na cidade do Rio de Janeiro, resolvi realizar um estudo aprofundado sobre tal expressão cultural dentro dessa região periférica. Iniciei em 2012 o curso de mestrado em Letras e Ciências Humanas pela Unigranrio, na linha de pesquisa Gênero, Etnia e Identidade.

O diálogo entre a cultura funk, relação étnico-racial e contribuição cultural africana permitiu explorar mais profundamente a cultura brasileira e, a partir desta investigação, desconstruir preconceitos e valorizar a diversidade. Conforme Lopes (2011), o racismo não é algo confesso, mas existe, e o preconceito ao funk significa considerá-lo uma manifestação rude, incivil e violenta, de forma que esse ritmo passa a ser visto como um movimento cultural desprezado e colocado à margem pela elite carioca, principalmente por ser formado na sua maioria por negros e pobres. Acrescenta ainda a autora que "o preconceito contra o 'batidão do funk' nada mais é do que uma atualização da discriminação contra os 'batuques do samba'” (LOPES, 2011, p. 61).

\footnotetext{
${ }^{2}$ A Lei no 10.639/03 alterou a LDB, Lei no 9.394/96, com a inclusão, no currículo oficial, da obrigatoriedade do ensino da História e Cultura Afro-Brasileira. A Lei no 11.645/08 alterou novamente a LDB, preservando a História e Cultura Afro-Brasileira e incluindo a História e Cultura Indígena.
} 


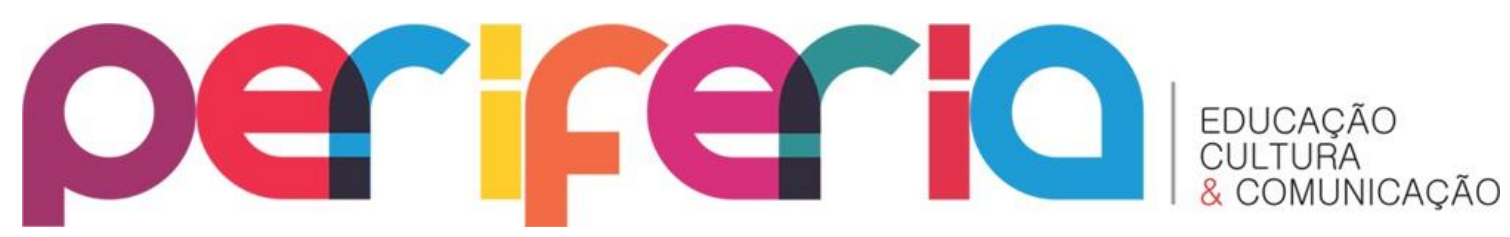

Nesse sentido, este artigo busca analisar o movimento funk, mas como identidade de um grupo específico, funkeiros na Baixada Fluminense, possibilitando despertar um novo olhar para essa expressão cultural, que traz consigo elementos da diáspora africana.

Para o desenvolvimento do trabalho, além das obras bibliográficas, contaremos com entrevista da MC Mary May, que iniciou sua carreira no ano de 2012, incentivada por seu amigo MC TG 10. MC é abreviatura de "mestre de cerimônia", denominação utilizada para os que cantam e improvisam nos bailes e shows, segundo Lopes (2011).

A MC Mary May fez teatro e não se imaginava como cantora, principalmente de funk. Já fez vários shows na Baixada Fluminense, mas atualmente realiza mais shows na cidade do Rio de Janeiro. O primeiro show que fez foi no América, em Mesquita, com a equipe de produção de bailes Tom \& Jerry. Algumas de suas músicas são: Me chama, Papo pras mandadas, Chegou a melhor hora (com David Bolado), Tio Sukita, Senta no Brinquedo (Baile do Pistão).

Também apresentaremos as ideias de MC Debby, que foi professora de balé clássico desde os 15 anos de idade. Tinha preconceito com o funk até que uma aluna que gostava do ritmo despertou-Ihe a curiosidade ao falar de James Brown. Como sempre gostou de arte, de ler e de estudar, resolveu pesquisar sobre o artista, o qual admira até hoje. Fez amizade com os MCs Esquisito e Ricardo, do Planeta Xuxa, que a convidou, a princípio, para dançar e depois para cantar com eles Tô ficando molhadinha. Após divergências, se separou e gravou várias outras músicas, como Vou dançar pelada, Segura seu namorado, Nóis incomoda, Hoje eu tô solteira, Deixa eu sarrar etc.

A outra entrevistada é Cristina da Conceição Silva, que atua profissionalmente na Baixada Fluminense como professora de História para alunos do segundo segmento do ensino fundamental (6 ao 9o ano) da Prefeitura Municipal de Nova Iguaçu e no curso de graduação na FEBF-UERJ, Duque de Caxias, na área de Etnia e Diversidade Cultural. Além de ser de pertença étnica afrodescendente, a entrevistada participou do movimento Black e participa do universo do samba. A professora trabalhou por 28 


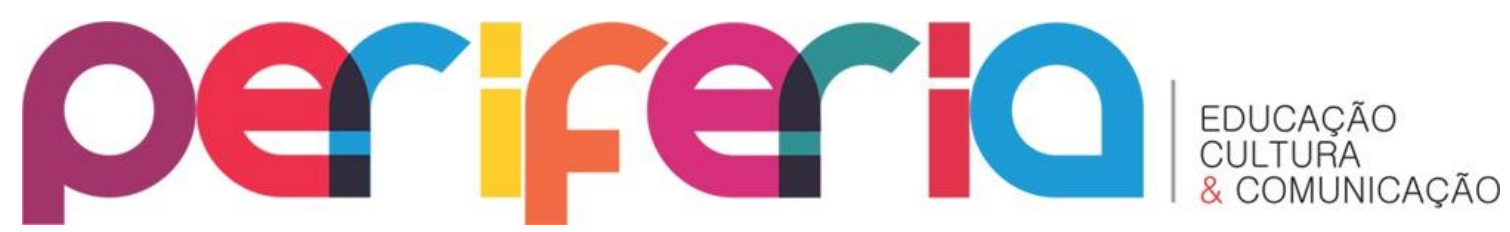

anos com jovens nas favelas de Acari, Pedreira e Morro do Lagartixa em projetos sociais promovidos pela Fundação Leão XIII e pela Secretaria Municipal de Assistência Social da Prefeitura da Cidade do Rio de Janeiro e acompanhou o envolvimento dos jovens com o ritmo funk. Nesse sentido, as experiências de Cristina são relevantes, pois trabalhar com negros e pobres, na sua maioria, permitiu-lhe observar o quanto esses grupos que adotam uma cultura adversa da elite, o funk, foram e em alguns casos ainda são marginalizados.

Enfim, as narrativas das entrevistadas, que são moradoras da Baixada e estão em contato com o movimento funk, são instrumentos valiosos, pois contribuem para um melhor esclarecimento sobre o assunto em questão.

\section{A HISTÓRIA DO FUNK NO RIO DE JANEIRO}

O funk, ritmo musical inventado por negros norte-americanos, desde o inicio da década de 1970 promove um grande número de festas frequentadas por jovens na cidade do Rio de Janeiro. Esses jovens são pertencentes às camadas mais pobres da população e têm no encontro um modelo barato de divertimento.

Conforme Essinger (2005) e Medeiros (2006), os primeiros bailes foram realizados na Zona Sul, no bairro de Botafogo, no antigo Canecão, com casa lotada, ao som de toca-discos e um bom jogo de luzes. No entanto, com a valorização da MPB (música popular brasileira), os bailes migraram para quadras esportivas e clubes no subúrbio do Rio de Janeiro e que conseguiam reunir em torno de 15 mil pessoas em cada evento, conforme Medeiros (2006).

De acordo com Vianna (1988), em 1987 aconteciam cerca de seiscentas festas de funk nos fins de semana na cidade do Rio de Janeiro, atraindo mais ou menos um milhão de pessoas. Esses números colocavam, na época, o baile funk como uma das diversões mais populares da cidade, depois da praia. Os jovens absorveram a dança, a música e o jeito de vestir dessa nova cultura e ritmo.

De acordo com Magnani (1982), para algumas pessoas a cultura do povo se transforma em instrumento de alienação, pois se descaracteriza sob a influência da 


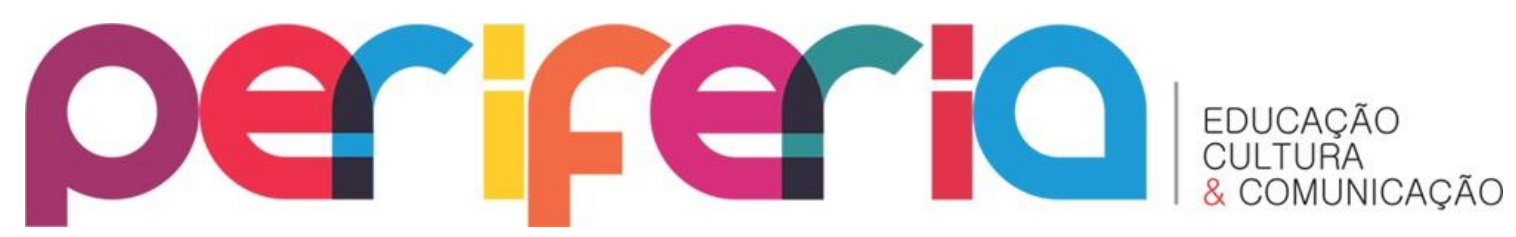

ideologia dominante; para outros, acontece o contrário: a cultura popular se torna um meio de resistência à dominação. Diante das considerações desse autor, é compreensível que muitos encarassem o novo ritmo e as absorções culturais dos jovens como modismo passageiro.

Conforme Vianna (1988), ao refletirmos sobre a nossa sociedade a respeito da indústria cultural e as políticas culturais oficiais, por um ou outro mecanismo, os padrões éticos e estéticos, dentre outros, são produzidos por especialistas em interesses da classe dominante e difundidos a toda a sociedade. E que, por esse mecanismo, procura-se criar uma ilusão de homogeneidade sobre um corpo social que, na verdade, é diferenciado. Seguindo essa linha de raciocínio, o autor relata que acabaríamos chegando à conclusão de que a indústria cultural fomentadora de homogeneização não é capaz de lidar com a heterogeneidade.

Para Mattelart (2010), a hegemonia é vista como relevante pela elite para preservar o poder e provocar a aceitação dos dominados aos valores e à produção que devem ser considerados vontade geral. No entanto, o movimento funk transgride essa hegemonia, pois apresenta a cultura com outros significados, deixando de ser domínio da tradição, passando a ser contemplados os gostos do povo, fugindo dos padrões estéticos e definidos por essa classe dominante.

O funk no Rio de Janeiro, aos olhos de Vianna (1988), não é uma imposição dos meios de comunicação de massa; pelo contrário, estes apresentam aspectos que ignoram o fenômeno. Segundo o autor, que aborda aspectos do fenômeno, na década de 1970 os discos que mais faziam sucesso não eram lançados no Brasil e as emissoras de rádio e televisão pouco espaço davam para os artistas brasileiros divulgarem seus funks e os jornais não anunciavam os bailes; mesmo assim, eles permaneciam lotados.

$\mathrm{O}$ desejo por funk parece algo interno à comunidade carioca que $\mathrm{O}$ consome, sem depender da ajuda ou incentivo de instituições externas. Os organizadores dos bailes cariocas desenvolvem várias estratégias para conseguir os discos que não são encontrados no mercado brasileiro (VIANNA, 1988, p. 4). 


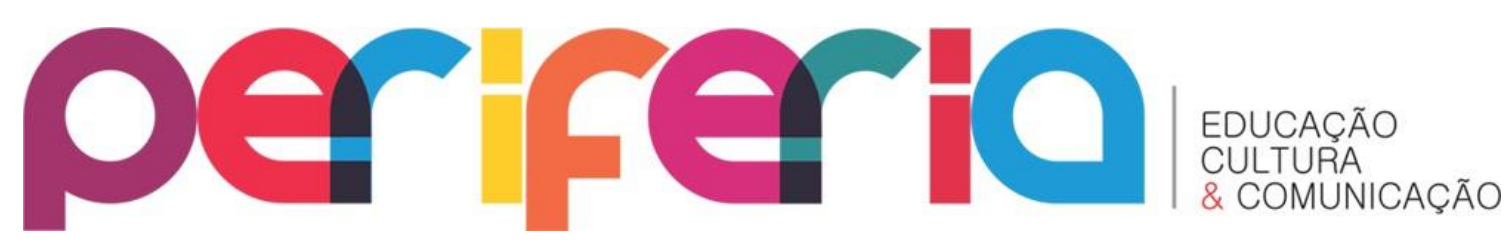

As dificuldades encontradas pelos funkeiros nesse período não pareciam desanimá-los; ao contrário, pareciam tornar mais excitante a prática do funk carioca. As disputas entre as grandes equipes de som, que conseguiam trazer os discos de fora, era tremenda, a ponto de os donos das equipes de som rasgar as capas dos discos para que outro não tivesse acesso ao sucesso norte-americano, comprado no mercado negro, como expõe Vianna (1988).

A história do funk não se baseia somente na importação de tradições musicais afrodescendentes dos Estados Unidos; segundo Facina (2009), trata-se de uma releitura de um tipo de música ligado à diáspora africana, ou seja, ao chegar ao Rio de Janeiro, esse ritmo importado passou a ser reinventado e renovado por ritmos negros que sempre existiram na periferia, complementa Lopes (2011).

\section{IDENTIDADE: O QUE É ISSO?}

Identidade, na época do lluminismo ou Época das Luzes³ ${ }^{3}$, conforme Hall (2001), nascia e se desenvolvia com o sujeito, como indivíduo centrado, unificado e dotado de capacidade de razão e de consciência e de ação e permanecia ao longo da existência do sujeito. O autor também comenta um segundo tipo de sujeito, o sociológico, que deixa de ser autônomo e autossuficiente, pois é formado na interação com outros, que medeiam valores, sentidos e símbolos (cultura), ou seja, a identidade é formada pela interação entre 'Eu' e sociedade, tornando os dois elementos mais unificados e predizíveis (é possível antecipa-los).

Hall (2001) comenta identidade de um terceiro sujeito, o pós-moderno. 0 indivíduo unificado e estável passa por transformações, deixando de ter identidade fixa ou permanente e se tornando fragmentado, uma vez que assume diferentes identidades em momentos diferentes. Esse processo de formação de identidades também envolve as identidades culturais, que se tornam mais variáveis.

\footnotetext{
${ }^{3}$ É uma doutrina filosófica e religiosa, que ocorreu na Europa no século XVIII e que provocou transformações na estrutura social. Os temas giravam em torno da Liberdade, Progresso e Homem. A intenção de corrigir as desigualdades sociais e garantir os direitos naturais do indivíduo, como liberdade e livres posses de bens.
} 


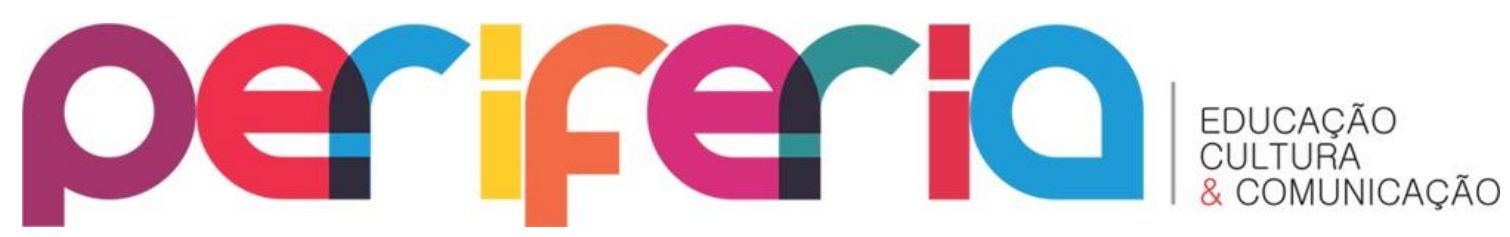

De acordo com Santos (1986), o pós-modernismo é o período em que ocorreram mudanças nas áreas das ciências e artes e nas sociedades avançadas; seu início se dá com o encerramento do Modernismo (1900-1950). Nasce com a Arquitetura e a Computação dos anos 1950, mas se fortalece com a Arte Pop dos anos 1960. Nos anos 1970, cresce com a Filosofia, que criticava a cultura ocidental, e, nos dias atuais, se difunde na moda, cinema, na tecnociência e na música. Ainda segundo esse autor, não se sabe se esse período é sinônimo de decadência ou renascimento cultural.

Nesse sentido, Hall (2001) afirma que o sujeito pós-moderno deixa as velhas identidades, as quais estabilizaram o mundo por muito tempo, e se permite possuir novas. Ele ainda comenta a crise de identidade, característica dos tempos atuais que faz parte de um processo de mudança que desequilibra as velhas estruturas dos estados, que antes davam segurança no mundo social, e é por isso que surge o declínio das "velhas certezas"; produz assim novas formas de posicionamento.

Existe, em suma, na vida moderna, uma diversidade de posições que nos estão disponíveis - posições que podemos ocupar ou não... Algumas dessas identidades podem, na verdade, ter mudado ao longo do tempo. As formas como representamos a nós mesmos como mulheres, como homens, como pais, como pessoas trabalhadoras - têm mudado radicalmente nos últimos anos. Como indivíduos, podemos passar por experiências de fragmentação nas nossas relações pessoais e no nosso trabalho. Essas experiências são vividas no contexto de mudanças sociais e históricas, tais como mudanças no mercado de trabalho e nos padrões de emprego. As identidades e as lealdades políticas também têm sofrido mudanças: lealdades tradicionais, baseadas na classe social, cedem lugar à concepção de escolha de "estilos de vida" e à emergência da "política de identidade". A etnia e a "raça", o gênero, a sexualidade, a idade, a incapacidade física, a justiça social e as preocupações ecológicas... As identidades sexuais também estão mudando, tornando-se mais questionadas e ambíguas, sugerindo mudanças e fragmentações que podem ser descritas em termos de uma crise de identidade (WOODWARD, 2000, p. 31).

D’Adesky (2009) comenta que as incompatibilidades (diferenças) provocadas pelas disparidades econômicas e distorções políticas geram em comunidades marginalizadas consciências favoráveis às reivindicações étnicas e culturais, de forma 


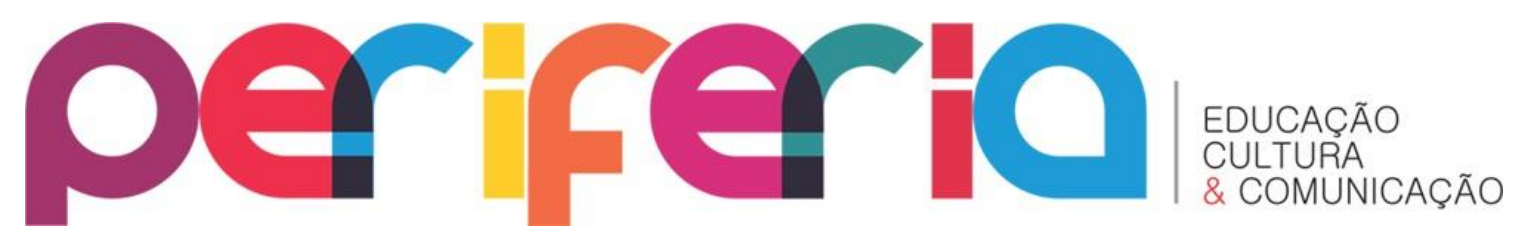

que funciona como instrumento que interpreta a situação, se posiciona e age sobre ela, denunciando a intenção de uniformização dos Estados nações, representados pelos pensamentos da elite. Bauman (2005) complementa que a contemporaneidade líquida não acredita mais na força coerção por parte do Estado, a sociedade não dá mais ordens de como viver e deixa de ser um árbitro severo e intransigente, mas se espera que seja justa e de princípios.

De acordo com Tomaz Tadeu da Silva (2000), a identidade é marcada pela diferença e por meio dela ocorre a separação de uma identidade da outra, estabelecendo distinções, e não uma relação de oposição, mas de dependência. 0 autor ainda expõe que tanto a identidade e quanto a diferença não são elementos naturais, mas fabricados a partir das relações sociais e culturais, pois a identidade não é fixa e estável, mas uma construção, de forma que se torna fragmentada.

Portanto, as diferentes identidades são possíveis, de maneira que justifica a representação da identidade funkeira pelo uso de determinada vestimenta, linguajar, comportamento etc. Vianna (1988) comenta que os jovens funkeiros tentam se vestir como a elite da Zona Sul. No início do movimento, a vestimenta masculina era semelhante à dos surfistas, mas com adaptações próprias, o que transformava os funkeiros em exóticos, pois exageravam nas cores, camisas abertas e cordões de prata.

Atualmente, os jovens ainda seguem padrões dos jovens da elite, usando roupas de marcas famosas e perfumes importados, mesmo que falsificados. O uso de cordões, pulseiras e anéis nas cores prata ou ouro, ainda continua em evidência, funciona como símbolo de poder e ostentação nas comunidades em que moram.

Quanto às mulheres, suas roupas são curtas e expõem o corpo. Vestidos colantes e justos, marcando as curvas, ou shorts e blusas curtas, também expondo a maior parte do corpo. Para as funkeiras, "esconder o corpo é suprimir as imagens que ele emite; cobri-lo equivale a dizer que ele não existe como algo que fala e se movimenta, como foco de erotismo. É reduzir o corpo, mesmo na gravidez, a algo pecaminoso e/ou ameaçador" (SILVA, 1999, p. 207). 


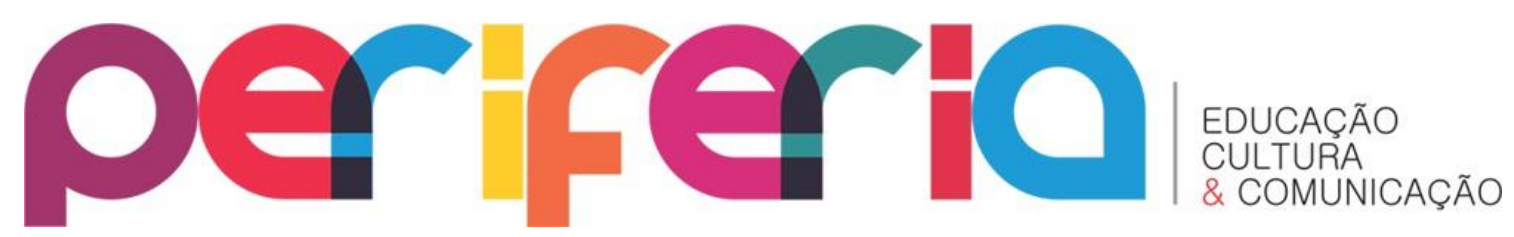

A moda das funkeiras recebeu o nome "piriguete", termo que surgiu na Bahia, na periferia de Salvador. Espalhou-se, por meio do funk, a ponto de se tornar um verbete no Dicionário Aurélio a partir de 2012, significando "mulher namoradeira". De acordo com Larangeira (2014), "piriguete" é uma mulher que foge às normas de conduta estabelecidas pela sociedade, como sexualidade, desejo e liberdade, o que the confere empoderamento.

As mulheres da sociedade, principalmente as jovens da elite, adotam também esse estilo, especialmente quando vão às festas e 'baladas' (entretenimento musical em casa noturna). Segundo Larangeira (2014), a simpatia das mulheres por esse tipo de vestimenta acontece não somente pelo sucesso com os homens, mas pelo simbolismo de poder ter o domínio de sua sexualidade. Nesse sentido, a autora conclui que as "piriguetes" acabam sendo classificadas como promíscuas, mas na verdade elas subvertem o jogo da sedução: a escolha de como usar o corpo é delas, e não dos homens.

\section{BAIXADA FLUMINENSE}

"Baixada" significa planície entre montanhas ou áreas baixas; "Fluminense" significa rio. De acordo com Duarte (2010), Baixada Fluminense se refere a terras baixas cortadas por rios como Meriti, Sarapuí, Pilar e Iguaçu. Atualmente, a Baixada Fluminense é formada pelos municípios de Itaguaí, Seropédica, Paracambi, Japeri, Queimados, Nova Iguaçu, Mesquita, Belford Roxo, Nilópolis, São João de Meriti, Duque de Caxias, Magé e Guapimirim. No entanto, este trabalho considerará os municípios de Nova Iguaçu, Mesquita, Belford Roxo, Nilópolis, São João de Meriti e Duque de Caxias.

De acordo com Marinho \& Martinez (2013), muitos dos municípios que compõem a Baixada Fluminense são oriundos do município de Nova Iguaçu, que foi fundado em 1833, e a partir de 1943 foi marcado por diversos desmembramentos. A partir desse ano, foram desmembrados os municípios de: Duque de Caxias, São João de Meriti, Nilópolis, Belford Roxo, Queimados, Japeri e Mesquita. 


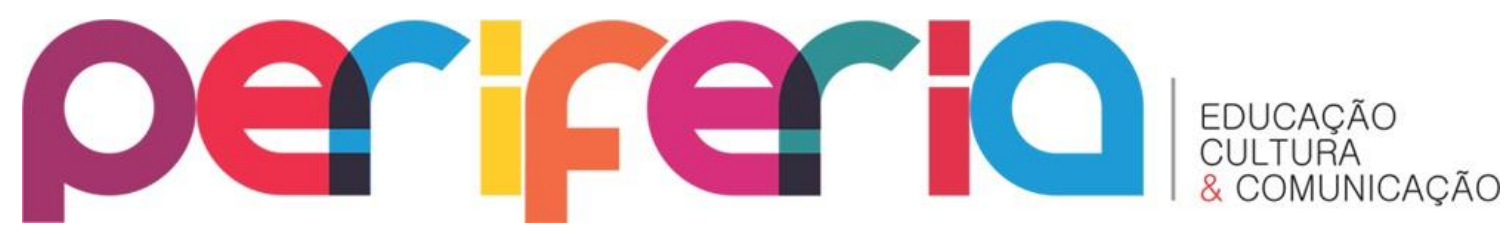

Nos anos 1960, segundo Santos (2008), como resultado da crise da citricultura e da conversão das chácaras em loteamentos, acontece elevado crescimento populacional com a chegada de uma população de baixa renda e de migrantes nordestinos. Ainda de acordo com esse autor, o abandono e a falta de investimento na infraestrutura em bairros da periferia pelo poder público que duram até os dias de hoje, estigmatizam a região como desvalorizada e ocupada por população de baixa renda, que, sem recursos econômicos e com a valorização das terras no Rio de Janeiro, encontrou a oportunidade de adquirir lotes baratos ou invadir terrenos particulares para fixar moradias.

Dessa forma, os municípios da Baixada Fluminense caracterizam-se como periféricos, densamente povoados e com problemas socioeconômicos similares. De maneira geral, sofrem com a ausência do poder político, evidenciada pela falta de infraestrutura social. A carência de creches e pré-escolas públicas aparece como uma dessas facetas de ausência do Estado, assim como a carência de serviços públicos nas áreas de saúde, cultura, esporte e lazer. Paralelamente, há o contexto da violência, tanto a praticada pelo tráfico de drogas e milícias quanto aquela proveniente do Estado (YOUNES IBRAHIM, 2012, p. 19).

A partir dos anos 1980, segundo Santos (2008), a Baixada Fluminense começou a modificar sua fisionomia, principalmente nos centros dos municípios, com criação de estradas e de condomínios, shopping centers etc.; todavia, na periferia dos centros, ainda há áreas de pobreza com carências urbanas e exclusão social, marcadas negativamente como regiões de índice elevado de criminalidade e violência.

Younes Ibrahim (2012, p. 18) comenta que, durante o século XX, a Baixada Fluminense continuou a receber muitos migrantes de várias regiões do Brasil em busca de soluções para graves crises, inclusive as econômicas, pois a cidade do Rio de Janeiro crescia nos moldes da modernidade, "o que implicou a retirada da população mais pobre da área central, realocando-a nas periferias sem a visibilidade da capital".

A Baixada Fluminense faz fronteira com a cidade do Rio de Janeiro, e, segundo Younes Ibrahim (2012), grande parte do desenvolvimento econômico e social está 


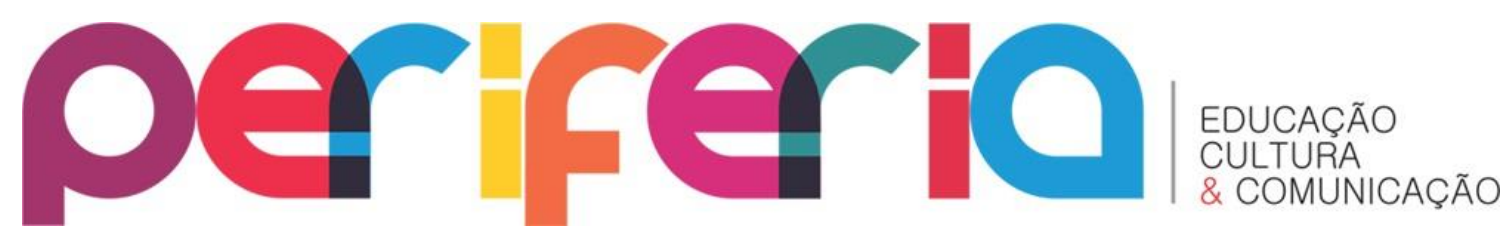

vinculado à capital. E não é diferente também com respeito a todas as manifestações sociais, políticas e culturais.

A chegada do movimento na Zona Sul, na década de 1970, adquirindo características brasileiras na década de 1980, pelo DJ Marlboro e se tornando um "som de preto e favelado, e quando toca ninguém fica parado..." (Som de Preto, de Amilcka e Chocolate), não demorou muito para atender aos anseios de diversão de negros e pobres da região periférica do Estado do Rio de Janeiro, a Baixada.

\section{OS BAILES NA BAIXADA FLUMINENSE}

De acordo com a historiadora Cristina da Conceição Silva, os jovens da Baixada veem nos bailes a única diversão barata, uma vez que muitas vezes acontecem em locais públicos, o que não gera custos, e, quando em lugares fechados, as mulheres não costumam pagar. Cada ida a baile se torna um evento que exige toda uma produção; no entanto, roupas e acessórios são trocados entre amigos, e cabelos, maquiagem e unha também são feitos por amigas. Nesse sentido, o movimento ganha força e receptividade.

Antes, o interesse maior dos jovens era para o pagode e o hip hop, mas o funk começou a se consolidar na região em questão e de uns cinco anos para cá se tornou um ritmo muito tocado e apreciado.

MC Mary May comenta que a Baixada é uma fábrica de MCs consagrados e de MCs do local, ou seja, pessoas que são MCs de determinada área. Alguns nomes de MCs no funk da Baixada são: MC Mg e MC Mary May em Mesquita; David Bolado e MC Tock, em São João de Meriti; e MC Rouba Cena, Pocahontas, MC Beyonce, MC Gibi, MC Luan em Duque de Caxias. Todavia, muitos desses MCs, apesar de serem da Baixada, acabam fazendo sucesso fora dessa região.

MC Debby, apesar de ser moradora da Baixada, conseguiu sua consagração em outros estados, como Rio Grande do Sul e Bahia, embora tenha sua música tocada no local em que mora e no Estado do Rio de Janeiro. Afinal, o funk é um ritmo surgiu no Rio de Janeiro, mas que contagiou todo o Brasil. 


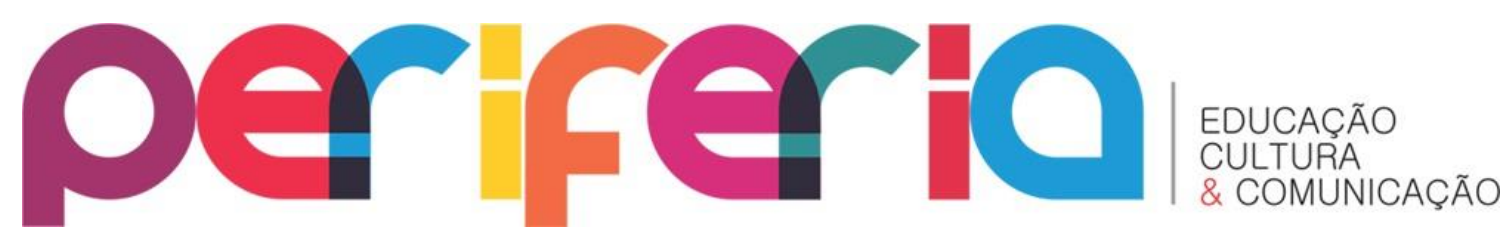

Os bailes da Baixada seguem os padrões dos que acontecem na cidade do Rio de Janeiro. Os homens pagam entrada e as mulheres, até meia-noite, não pagam. Os eventos costumam reunir em torno de quatro a seis mil jovens, e a escolha das atrações é feita a partir do sucesso da época, via empresários ou assessores, porém podem ser MCs conhecidos e consagrados ou MCs locais, que a mídia não divulga, mas são do conhecimento dos que apreciam o ritmo.

MC Mary May explica que os MCs cantam músicas próprias, mas, em geral cantam músicas que estão com maior sucesso no momento, principalmente em casas de show ou boates que possuem contato com o Ecad (Escritório Central de Arrecadação), órgão particular que tem a função de arrecadar os direitos autorais das músicas tocadas nas rádios, televisão, em casas de show e boates. Nas comunidades, os MCs tendem a cantar suas próprias músicas.

Os MCs realizam vários shows em uma noite, chegando a uma média de sete, sendo o último muitas vezes pela manhã. Os shows podem ser compartilhados, quando o MC se apresenta com a atração principal ou, se é a atração principal, divide o palco com outros com pouca expressão no meio, ou com uma atração, quando só o MC se apresenta. Um show tem a duração de 20 minutos; quando é completo, com DJ, abertura e dançarinos, esse tempo aumenta para 30 a 35 minutos. Em alguns casos, o tempo no palco é cronometrado; de acordo com MC Debby, principalmente quando você está no início de carreira, se ultrapassar esse tempo desligam o microfone.

A MC comenta que o início de carreira para um MC é muito difícil, muitos começam cantando de graça ou por valor irrisório. Como há muitos MCs, as casas de shows e contratantes de eventos não os valorizam. O preconceito com os funkeiros faz com que a sociedade não encare os MCs como artistas, e sim pessoas com grande apelo sexual falando coisas engraçadas.

A faixa etária dos frequentadores dos bailes varia, em média, entre 13 e 25 anos; eles costumam andar em grupos de amigos. Muitos vão a pé para os eventos, quando no mesmo bairro ou em bairros vizinhos, chegando às vezes andar 20 a 30 minutos; alguns vão de moto ou carro. Quando os bailes acontecem mais longe, 


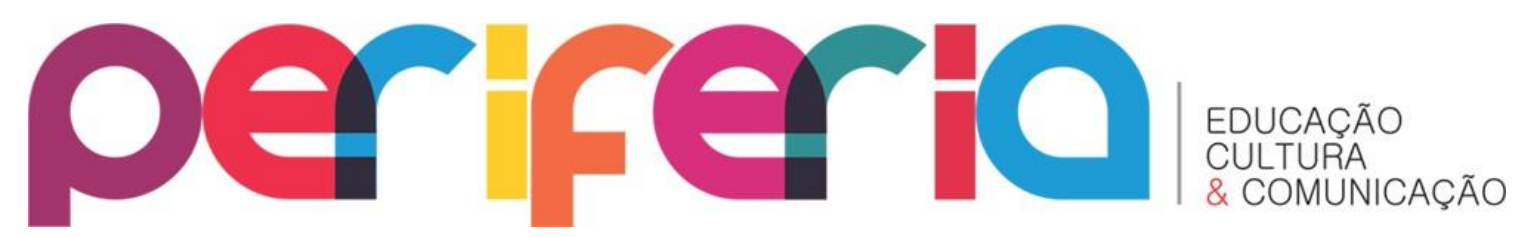

utilizam o ônibus, porque muitos que andam de moto ou carro não possuem carteira de habilitação ou são menores. MC Mary May comenta que os bailes não podem ser frequentados por menores, mas os seguranças e recepcionistas não têm como controlar, pois muitos adolescentes aparentam serem maiores de idade pelo físico, vestimenta e maquiagem, e acabam entrando. Já nos bailes de rua e quadras, não existe esse controle.

O movimento é predominantemente frequentado por jovens; na sua maioria, após a fase adulta há diminuição. Provavelmente isso ocorre devido às responsabilidades adquiridas com família e trabalho.

$\mathrm{Na}$ Baixada, existem as equipes que realizam os bailes em lugares fechados, como boates, salões e quadras de clubes; cada grupo é referência em seu município. Em Nova Iguaçu, as equipes mais conhecidas são Fura Olho, Dente de Aço, Pit Bull, Pink e Cérebro, Atrás Amiguinhas. Em São João de Meriti tem Vem quem pode; em Mesquita, Tom e Jerry; em Duque de Caxias, algumas das equipes são Pantanal Sons, Pedrinha do Sapo e Pica Pau.

Na Baixada há dois tipos de bailes. No baile social, que equivale a uma festa, equipes ou amigos se reúnem, alugam um espaço, como salão de festa ou clubes pequenos, contratam algum MC e organizam um show. É cobrada a entrada por pequeno valor. Em Mesquita, tem o Clube do Rocha; em Nova Iguaçu, acontece o Baile da Piscina.

Os bailes propriamente ditos são realizados em casas de show ou nas ruas, numa proporção maior: aparelhagem melhor, MCs com maior destaque no bairro ou em evidência e maior público. Em Mesquita, tinha o Baile da Coreia, que, por força policial, teve que parar a partir de maio de 2014. Em Belford Roxo, há o Baile do Castelar, que até final do ano de 2013 era na rua e agora é realizado em uma quadra; tem o Baile do São Vicente, Palmeira, e Caixa D'água, que ainda acontecem na rua. Duque de Caxias é um município onde ocorrem muitos bailes dentro de comunidades, como Baile Beira Mar, Baile do Bananal, Baile do Sapo, Baile do Pantanal. 


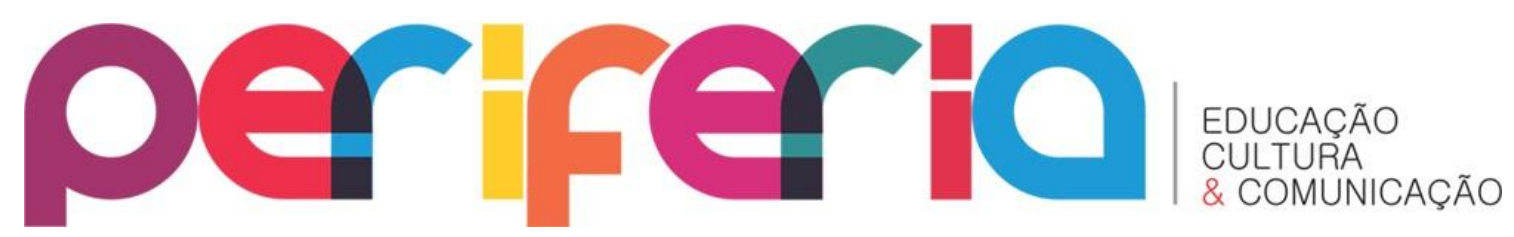

Os bailes são divulgados pela rede social Facebook, cartazes e carros de som. Os bailes sociais acontecem mais cedo, por volta das $21 \mathrm{~h}$, e terminam à meia-noite. Alguns começam mais cedo ainda, por volta de $17 \mathrm{~h}$. Já os bailes de rua e de casas de show acontecem geralmente aos sábados e costumam começar às $22 \mathrm{~h}$ e terminar às $5 \mathrm{~h}$ do dia seguinte (domingo).

Em Mesquita, o baile de clube ou casa de show mais conhecido é o Tênis Clube de Mesquita; em Nova Iguaçu, tem o Rio Sampa e Gregos e Troianos; Via Show, em São João de Meriti; em Nilópolis acontecem bailes na Quadra da Beija-Flor. Quanto às danças, um começa e os outros vão fazendo o mesmo passo, colocando seu estilo. Ainda quanto às danças, nos bailes o que chama muito a atenção, principalmente do sexo oposto, é a dança do passinho.

\section{DANÇA DO PASSINHO}

A dança associada ao ritmo sempre esteve presente nas civilizações e é um elemento de representação identitária. O corpo está diretamente relacionado à dança, uma vez que se torna instrumento para executar movimentos.

Em 2001, surgiu nas favelas do Rio de Janeiro um jeito novo de dançar o funk, denominado "dança do passinho"; o passinho tomou força em 2008, com o vídeo Passinho Foda, que teve mais de quatro milhões e meio de visualizações no YouTube, segundo o site Carta Capital (2013). Escosteguy (2013) declara que a mídia e a tecnologia entram no contexto da vida cotidiana a partir da década de 1980, fazendo com que a cultura popular fosse entendida como autônoma e resistente ao campo hegemônico.

O escritor Julio Ludemir e o músico Rafael Nike, ainda de acordo com o site Carta Capital (2013), organizaram uma competição que formalizou os duelos, chamada "Batalha do passinho", que antes era reservada à internet e aos bailes; o primeiro evento foi realizado em setembro de 2011.

No funk, antes eram populares a figura do MC, do DJ. Com o passinho, ganha um novo status a pessoa que está na pista, o dançarino. Os caras começam a ficar populares com as mulheres no 


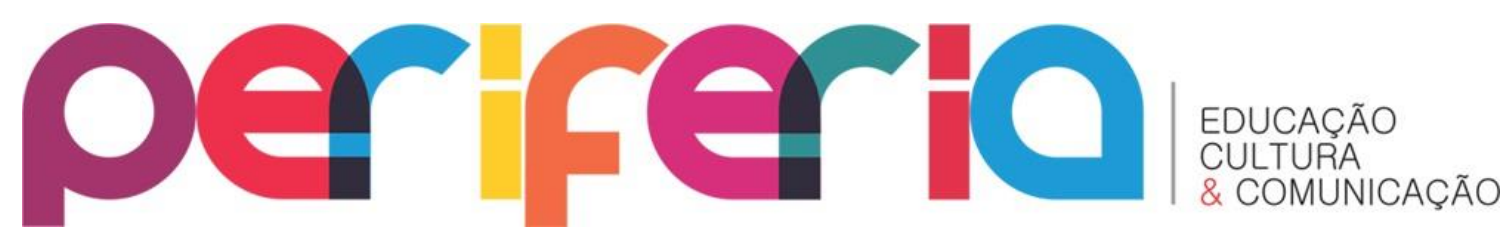

baile, e o fato de estarem no meio do público faz com que as pessoas se identifiquem ainda mais com eles... Com o passinho, houve uma valorização das montagens e da dança. As letras são mais sintéticas e costumam falar da própria dança, a ênfase é no ritmo. Há entre os dançarinos uma relação lúdica com o passinho. Mas, ao mesmo tempo, sonham em fazer sucesso, viver da dança, eles têm orgulho em mostrar o talento e representar a comunidade deles. Domingos sobre a diferença com os outros funks (DOMINGOS, apud CARTA CAPITAL, 2013).

Ainda de acordo com a entrevista do cineasta Domingos, sócio da Osmose Filmes e diretor de Batalha do passinho: o filme, na matéria 'A Batalha do Passinho' retrata febre que tomou o Rio, da Carta Capital de 7 de outubro de 2013, o passinho é um ritmo antropofágico, pois "as pessoas rotulam o fenômeno como uma mistura de funk, frevo, break e samba, o que eu acho muito reducionista. A meu ver, incorpora também mímica, kuduro, ioga, contorcionismo, capoeira". Vianna (1988) comenta que seria mais natural ter um baile de samba, de rock ou qualquer outra música de fácil disponibilidade, mas a ideia de antropofagia de Oswald de Andrade, de "interessar-me pelo que não é meu" fez com que surgisse interesse dos discotecários pela raridade. Nesse sentido, o funk no Rio de Janeiro passou a ser inédito, a ponto de não existir bailes como esses em outro lugar.

Alguns detalhes aparecem em outras cidades. Mas a combinação
desse tipo de dança com o tipo de roupa, com o tipo de música, com
o tipo de organização das equipes de som e a atuação do DJ só
acontece no mundo funk carioca. E muito além da antropofagia: o
Rio não devolve para o mundo uma outra maneira de se fazer hip
hop. Tudo termina no baile (VIANNA, 1988, p. 132).

As danças e o movimento dos negros africanos escravizados se tornaram base para os ritmos dos tempos atuais, por meio da recriação e da transformação a partir do contato com outros povos. O corpo, no funk, se envolve com a música comandada pela batida e, como uma brincadeira, vive intensamente cada movimento, "proporcionando ao seu corpo apenas reflexo, que não é determinado pela razão, mas, quem sabe, por uma improvisação que a ocasião corporal lhe solicite" (SILVA, 2003, p. 63). O movimento do corpo no funk apresenta conexão com o ritmo, que é envolvente e estimulante, fortalecendo e firmando os valores identitários. 


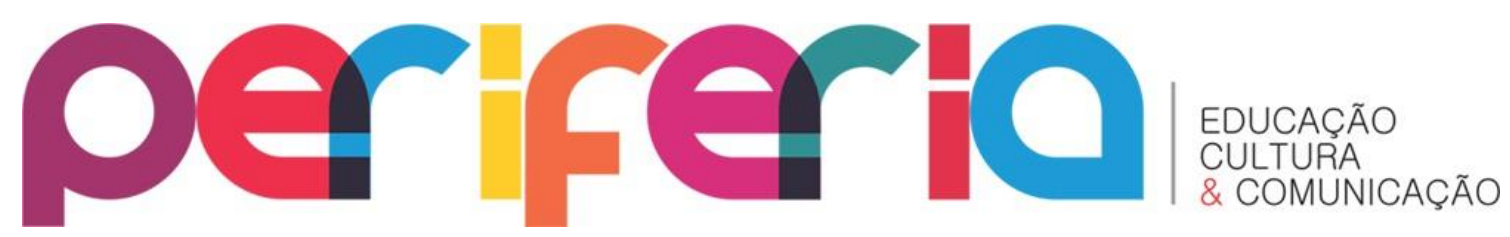

Em 2013, a Batalha do Passinho, que acontecia nas favelas do Rio de Janeiro, passou a fazer parte da vida dos dançarinos funkeiros da Baixada Fluminense. Rafael Nike, idealizador da Batalha e morador de Nova Iguaçu, trouxe esse campeonato também para a região da Baixada Fluminense.

A primeira etapa foi em Belford Roxo, na Praça Eliaquim Batista, no dia 27 de setembro de 2013. A segunda eliminatória foi no município de Mesquita, no dia 29 de setembro, no Paço Municipal; a final foi realizada em Nova Iguaçu, no dia 5 de outubro.

Segundo o site Sopa Cultural $(2013)^{4}$, a competição consistiu em cada dançarino mostrar suas habilidades em 45 segundos, sendo avaliados por três jurados; no ano de 2013, foram o jornalista e apresentador Pedro Bial (júri artístico), a atriz Cris Amadeo (júri técnico) e a atriz Juliana Alves (júri artístico). A grande final contou com 16 competidores, ficando o primeiro lugar com o prêmio de $\mathrm{R} \$ 5.000,00$, o segundo com $\mathrm{R} \$ 1.000,00$ e o terceiro classificado ganhou o valor de $\mathrm{R} \$ 500,00$. O ganhador da Batalha do Passinho Baixada 2013 foi Danilo Pelúcia; J. Pedro Mr. Passista ficou com o segundo lugar e o terceiro foi para Yussef.

\section{CONSIDERAÇÕES FINAIS}

O presente artigo esclareceu que as questões identitárias do funkeiro na Baixada Fluminense refletem o mundo pós-moderno, em que o indivíduo não mais possui uma identidade única, submetida aos valores e padrões do Estado, como elemento de representação da sociedade dominante; é possível a ele possuir identidades diversas em momentos diferentes, que atendam suas expectativas.

Um dos fatores que contribuiu para o surgimento e crescimento do movimento funk na Baixada Fluminense foi a proximidade com a cidade do Rio de Janeiro, onde o movimento nasceu, pois, à medida que foi se expandindo para a periferia, não demorou muito para atingir os jovens negros e pobres dessa área. Junto com a

\footnotetext{
${ }^{4}$ Disponível em: http://www.sopacultural.com/batalha-do-passinho-chega-na-baixada-fluminense/
} 


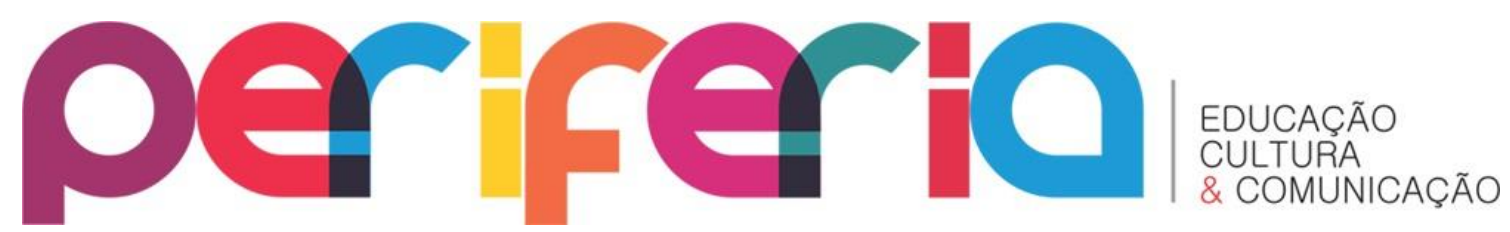

absorção dessa expressão cultural, vieram também vários elementos com significados identitários, como vestimenta, linguajar, postura, ritmo e dança.

A dança, junto com o ritmo, reconstrói e transforma o mundo; no funk, representa a reafirmação da identidade dos pobres e negros discriminados por sua condição e sua cultura por uma classe elitista que determina valores culturais e padrões clássicos. Nesse contexto, surgiu a dança dos passinhos, que assumia uma postura de resistência diante dessa sociedade dominante, uma vez que fica evidente a diáspora africana, pela mistura de samba, capoeira, break etc., culturas que sofreram com a discriminação e o preconceito ao longo da história, apesar de ter atualmente, reconhecimento.

As reflexões acerca do movimento funk na Baixada Fluminense nos levam à compreensão de que, para os jovens, trata-se de uma referência identitária, uma vez que é um movimento cujo discurso ultrapassa os limites de gênero musical, representando espaço de valorização individual e coletiva em que age como protagonista e não figurante no cenário em que a elite domina.

\section{REFERÊNCIAS}

BAUMAN, Zygmunt Identidade. Trad. Carlos Alberto Medeiros. Rio de Janeiro: Jorge Zahar, 2005.

D'ADESKY, Jacques. Pluralismo étnico e multi-culturismo: racismo e anti-racismos no Brasil. Rio de janeiro: Pallas, 2009.

DUARTE, Paula Alves. História ambiental de uma unidade de conservação: o Parque Municipal de Nova Iguaçu. Dissertação (Mestrado em Geografia). Universidade do Estado do Rio de Janeiro, Instituto de Geografia. Rio de Janeiro, 2010.

ESCOSTEGUY, Ana Carolina. Os estudos culturais. Cartografia - website de estudos culturais. Disponível em http://www.pucrs.br/famecos/pos/cartografias/. Acesso em 26 jun. 2013.

ESSINGER, Silvio. Batidão: uma história do funk. Rio de Janeiro: Record, 2005.

FACINA, Adriana. Que batida é essa? In: CASTRO, André; HAIAD, Julia (Org.). Funk, que batida é essa? Rio de Janeiro: Aeroplano, 2009.

GOMBATA, Marsília. "A Batalha do Passinho" retrata febre que tomou o Rio. Carta Capital, $07 \quad$ out. 2013.2 Disponível em http://www.cartacapital.com.br/cultura/mergulho-antropologico-a-batalha-dopassinho-retrata-febre-que-tomou-o-rio-1348.html. Acesso em 05 ago. 2014. HALL, Stuart. Identidade cultural na Pós-modernidade. Rio de Janeiro: DP\&A, 2001. 


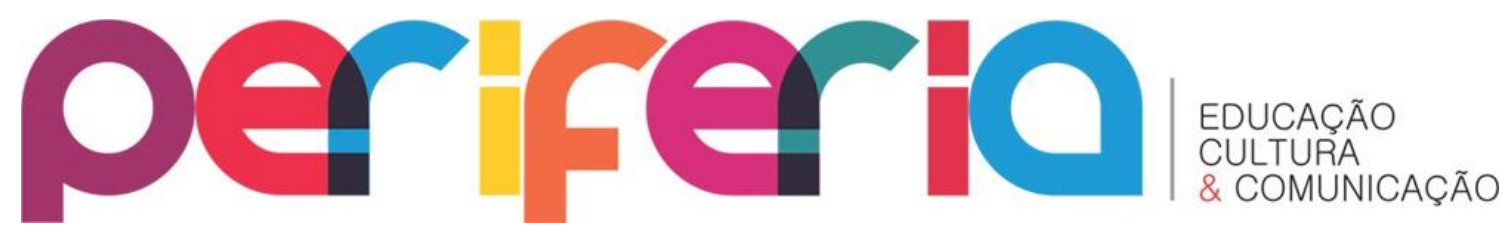

LARANGEIRA, Larissa Quillinan Machado. Piriguetes no funk carioca. 29a Reunião Brasileira de Antropologia, 03 e 06 de agosto de 2014, Natal/RN. Disponível em: http://www.29rba.abant.org.br/resources/anais/1/1401628805 ARQUIVO piriguetes nofunkcariocaRBA.pdf. Acesso em 06 out. 2014.

LOPES, Adriana Carvalho. Funke-se quem quiser: no batidão negro da cidade carioca. Rio de Janeiro: Bom Texto, 2011.

MAGNANI, José Guilherme Cantor. Cultura popular: controvérsias e perspectivas. BIB, no 12, 1982.

MARINHO, Ricardo José de Azevedo \& MARTINEZ, Márcia de Castro. A construção espacial de Nova Iguaçu. Revista Pilares da História, Ano 12, no 13.Instituto Histórico Vereador Thomé Siqueira Barreto/Câmara Municipal de Duque de Caxias e Associação dos Amigos do Instituo Histórico. 2013.

MATTELART, Armand; NEVEU, Érik. Introdução aos estudos culturais. Parábola Editorial: 2010.

MEDEIROS, J. Funk carioca: crime ou cultura? O som dá medo. E prazer. São Paulo: Terceiro Nome, 2006.

SANTOS, Jair F. dos. O que é pós-moderno. São Paulo: Brasiliense, 1986.

SANTOS, Everaldo Lisboa dos. Reorganização espacial na área central de Nova Iguaçu: o centro velho e o centro novo. Dissertação (Mestrado em Geografia). Universidade do Estado do Rio de Janeiro, Instituto de Geografia. Rio de Janeiro, 2008.

SILVA, Geysa. A subjetividade feminina entre o humor e a memória. In: RAMALHO, Christina (org.). Literatura e feminismo - propostas teóricas e reflexões críticas. Rio de Janeiro: Elo, 1999.

SILVA, José Milton Ferreira da. A linguagem do corpo na capoeira. Rio de Janeiro: Sprint, 2003.

SILVA, Tomaz Tadeu da. A produção social da identidade e da diferença. In: SILVA, Tomaz Tadeu da (org.). Identidade e diferença: a perspectiva dos estudos culturais. Petrópolis: Vozes, 2000.

SOPA CULTURAL. Batalha do Passinho na Baixada Fluminense. Notícias, 17 set. 2013. Disponível em: http://www.sopacultural.com/batalha-do-passinho-chega-na-baixadafluminense/. Acesso em 5 nov. 2013.

VIANNA, Hermano. O mundo funk carioca. Rio de Janeiro: Jorge Zahar, 1988.

YOUNES IBRAHIM, Suzete. $O$ amanhã que a gente tece: práticas em educação infantil comunitária na Baixada Fluminense. Rio de Janeiro: SFB, 2012. 